\title{
Body-Worn Spiral Monopole Antenna for Body-Centric Communications.
}

\author{
Kammersgaard, Nikolaj Peter Iversen; Kvist, Søren H.; Thaysen, Jesper; Jakobsen, Kaj Bjarne
}

Published in:

Proceedings of the 2015 International Workshop on Antenna Technology

Publication date:

2015

Document Version

Publisher's PDF, also known as Version of record

Link back to DTU Orbit

Citation (APA):

Kammersgaard, N. P. I., Kvist, S. H., Thaysen, J., \& Jakobsen, K. B. (2015). Body-Worn Spiral Monopole Antenna for Body-Centric Communications. In Proceedings of the 2015 International Workshop on Antenna Technology (pp. 107-110). IEEE.

\section{General rights}

Copyright and moral rights for the publications made accessible in the public portal are retained by the authors and/or other copyright owners and it is a condition of accessing publications that users recognise and abide by the legal requirements associated with these rights.

- Users may download and print one copy of any publication from the public portal for the purpose of private study or research.

- You may not further distribute the material or use it for any profit-making activity or commercial gain

- You may freely distribute the URL identifying the publication in the public portal 


\title{
Body-Worn Spiral Monopole Antenna for Body-Centric Communications
}

\author{
Nikolaj P. I. Kammersgaard ${ }^{* \dagger}$, Søren H. Kvist ${ }^{\dagger}$, Jesper Thaysen ${ }^{\dagger}$ and Kaj B. Jakobsen* \\ npivka@elektro.dtu.dk, skvist@gnresound.com, jthaysen@gnresound.com, kbj@elektro.dtu.dk
}

*Department of Electrical Engineering, Electromagnetic Systems, Technical University of Denmark, Ørsteds Plads, Building 348, DK-2800 Kgs. Lyngby, Denmark

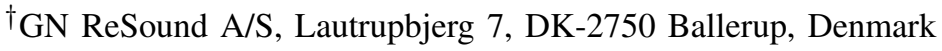

\begin{abstract}
A novel body-worn spiral monopole antenna is presented. The antenna consists of a ground plane and a spiral monopole. The antenna is designed for Ear-to-Ear (E2E) communication between In-the-Ear (ITE) Hearing Instruments (HIs) at $2.45 \mathrm{GHz}$ and has been simulated, prototyped and measured. The antenna yields a measured and simulated Ear-toEar path gain at $2.45 \mathrm{GHz}$ of $-82.1 \mathrm{~dB}$ and $-85.9 \mathrm{~dB}$, respectively. The radiation pattern of the antenna when mounted in the ear is presented and discussed.
\end{abstract}

\section{INTRODUCTION}

Research in body-worn antennas for body-centric communication has increased in the last decade. Ever smaller electronics have enabled a wide range of new applications where wireless communication can be implemented. Many of these new applications have been within health equipment. One of these is for HIs. In the HI industry there is an interest in obtaining E2E communication between the HIs. An E2E link improves the acoustic performance of the HIs as well as the usability. Besides E2E communication there is an interest in communication with both on- and off-body accessories. By the use of the license free and worldwide Industrial, Scientific and Medical (ISM) band between $2.40 \mathrm{GHz}$ and $2.48 \mathrm{GHz}$ both E2E and accessory communication can be obtained. At the same time it will enable communication with electronics with Bluetooth. Antennas suitable for Behind-the-Ear (BTE) HIs have been presented in the literature with an E2E path gain of $-52 \mathrm{~dB}[1]$. The ITE antennas that has been presented in the literature have not yielded E2E path gains significantly above $-90 \mathrm{~dB}$ [2], [3]. In the following a novel ITE antenna which is the first to make E2E communication feasible between ITE HIs is presented. The antenna was first presented briefly in [4]. Here the antenna is presented in depth and new results are presented.

\section{THEORY}

At $2.45 \mathrm{GHz}$ the human body is very lossy [5]. Therefore, the electromagnetic energy can not propagate through the body. It has been shown that the electromagnetic energy propagates around the human body as creeping waves instead [6]. Models for the E2E propagation channel have been presented in [7], [8]. These models estimate the E2E path gain by the

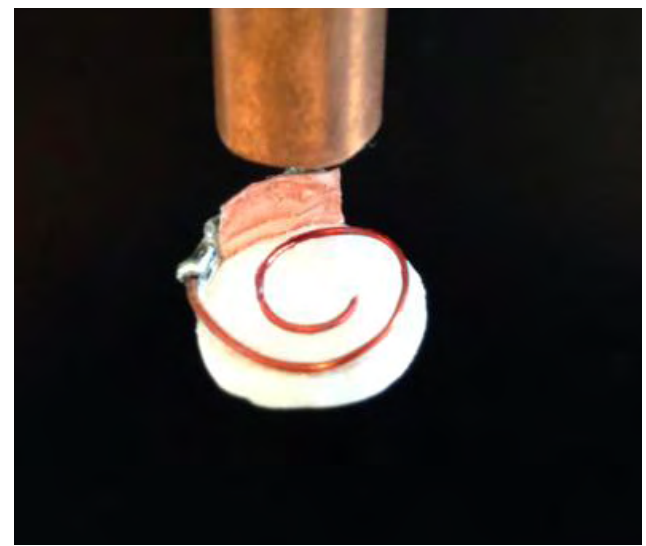

Fig. 1. The fabricated prototype of the spiral monopole antenna. The connected coaxial cable and balun are seen at the top.

use of a number of elliptic paths around the head. For each of these paths an estimate of the magnitude of the creeping wave launched in each path is made. The attenuation along each path is calculated by a closed form expression. Finally, the contributions of each of the paths are added to give the path gain. In [8] the on-body gain is used to estimate the magnitude of the launched creeping waves. The on-body gain will be used to evaluate the radiation pattern of the antenna presented here. The phase of the electric field has been included in the onbody gain to account for the initial phase differences in the launched creeping waves. This means that the on-body gain is an untraditional gain that has both a magnitude and a phase, which can be expressed as:

$$
G_{\text {on-body }}(\phi)=\int_{0}^{\pi} G_{\theta}(\theta, \phi) e^{j L E_{\theta}(\theta, \phi)} \sin \theta \mathrm{d} \theta
$$

where $G_{\theta}(\theta, \phi)$ is the $\theta$-component of the gain for the antenna mounted on the head, and $E_{\theta}(\theta, \phi)$ is the $\theta$-component of the electric field for the antenna when it is mounted on the head. It is noted that it is only the $\theta$-component that is included in the equation. This is due to the fact that the $\phi$-component is attenuated much faster than the $\theta$-component [9]. 


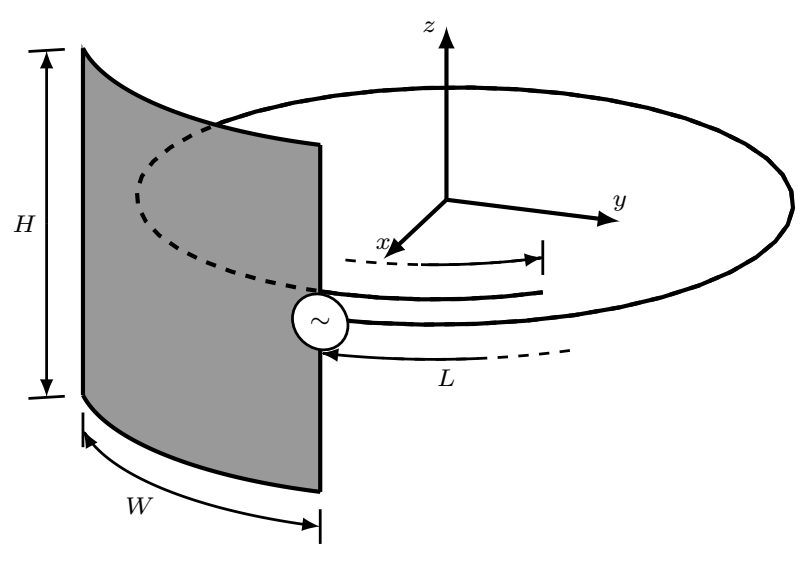

Fig. 2. The spiral monopole antenna.

TABLE I

OPTIMIZED ANTENNA DESIGN PARAMETERS

\begin{tabular}{lr}
\hline Parameter & $\begin{array}{r}\text { Value } \\
(\mathrm{mm})\end{array}$ \\
\hline \hline$L$ & 31 \\
$r$ & 0.10 \\
$W$ & 6.0 \\
$H$ & 5.0 \\
$R$ & 5.0 \\
$d$ & 1.0 \\
\hline
\end{tabular}

\section{EXPERIMENTAL SETUP}

The antenna consists of a ground plane connected to a monopole with radius $r$. The antenna can be seen in Fig. 2 . An advantage of this design is that the electronics for the HI could be placed on the ground plane. To reduce the size the monopole is spiraled with a spiral radius $R$ that is reduced by $d$ for each turn. The parameters used can be seen in Table I. The antenna is self resonant since the length of the monopole corresponds to proximately a quarter wavelength at $2.45 \mathrm{GHz}$. The antenna was matched for $50 \Omega$. The antenna was placed in the ear so the plane of the spiral monopole (XY-plane in Fig. 2) coincides with the surface of the head. This means that seen from the front of the head, the antenna is completely hidden by the tragus, i.e., the cartilaginous fleshy projection that partially covers the entrance to the external ear.

Simulations were done in ANSYS HFSS 2014. The Specific Anthropomorphic Mannequin (SAM) fitted with realistic ear was used. The head and ears were given homogeneous electrical parameters of $\epsilon_{\mathrm{r}}=50$ and $\tan \delta=0.5$. The antenna was modeled as copper. The simulation setup can be seen in Fig. 3. It is noted that the coordinate systems indicated in Fig. 3a and Fig. 2 are the same.

The prototype used for the measurements can be seen in Fig. 1. ROHACELL ${ }^{\circledR} \mathrm{HF}\left(\epsilon_{\mathrm{r}}=1.05\right.$ and $\left.\tan \delta<0.0002\right)$ was used to support the antenna. The antenna was fed from a coaxial cable connected to a Vector Network Analyzer. The cable was fitted with a balun to reduce the currents on the cable. The measurements were done in a radio anechoic chamber.

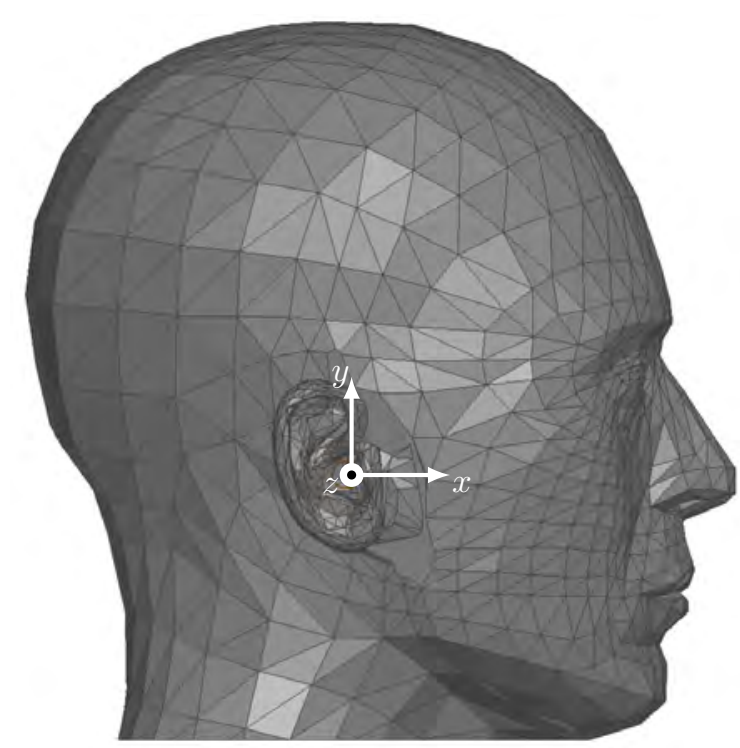

(a)

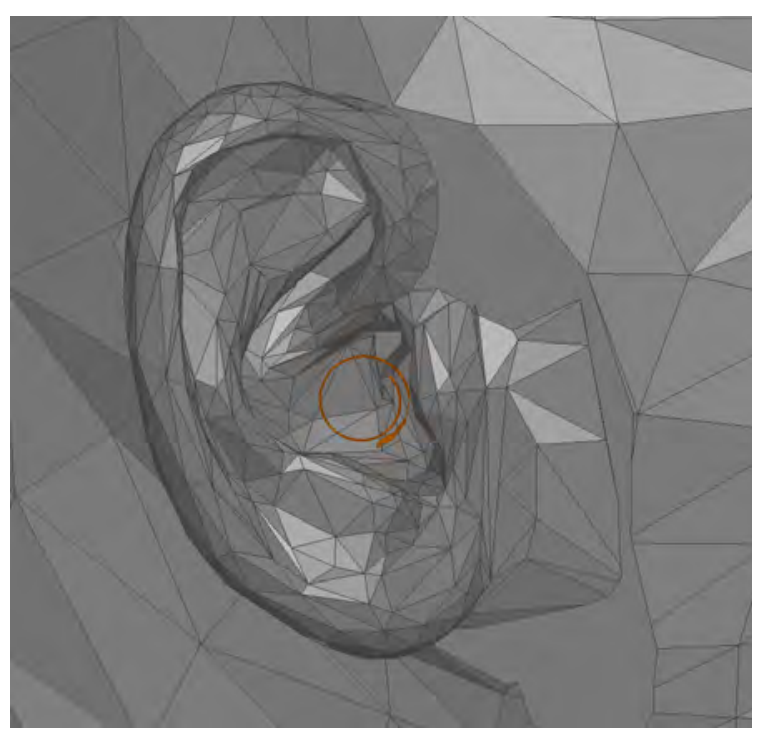

(b)

Fig. 3. The SAM phantom head (a) with the coordinate system used and the realistic ear (b) where the antenna can be seen (orange)

\section{RESUlTS AND Discussion}

The simulated and measure E2E path gain can be seen in Fig. 4. In the entire ISM band the simulated and measured path gain is better than $-86.7 \mathrm{~dB}$ and $-83.5 \mathrm{~dB}$, respectively. It is noted that this is within the dynamic range of many standard Bluetooth ICs. Since the antenna is completely $\phi$ polarized in free space it might be possible to obtain a better path gain with a $\theta$-polarized antenna as shown for BTE antennas [10]. The simulated and measured reflection coefficient plotted in a Smith chart can be seen in Fig. 5. As seen the antenna is matched for the entire ISM band. The measurement and simulation results correspond well. It is seen that the measurements are more broadband than the simulations. One of the possible causes are higher loss in the 


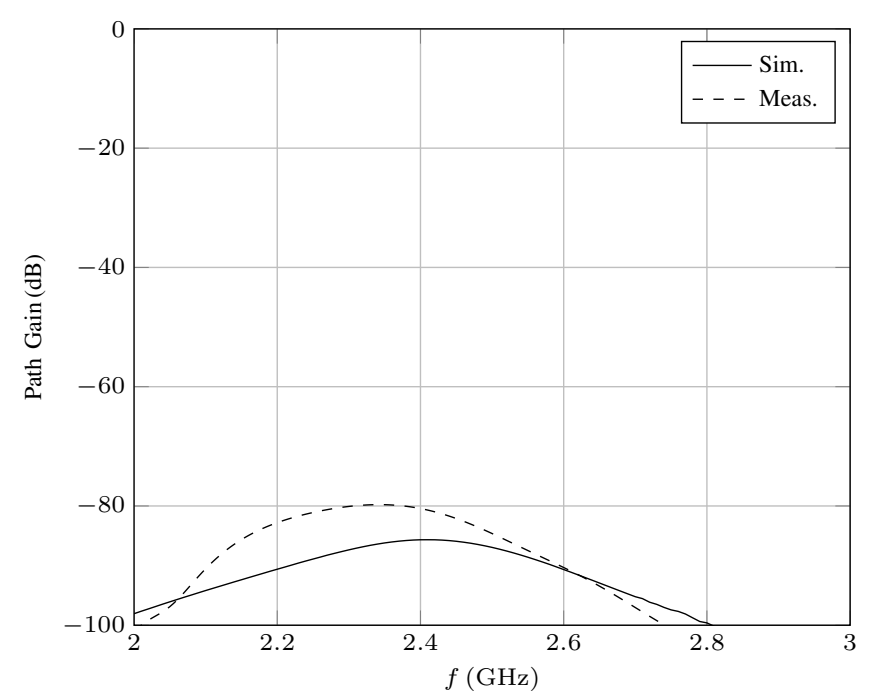

Fig. 4. Simulated (solid line) and measured (dashed line) E2E path gain.

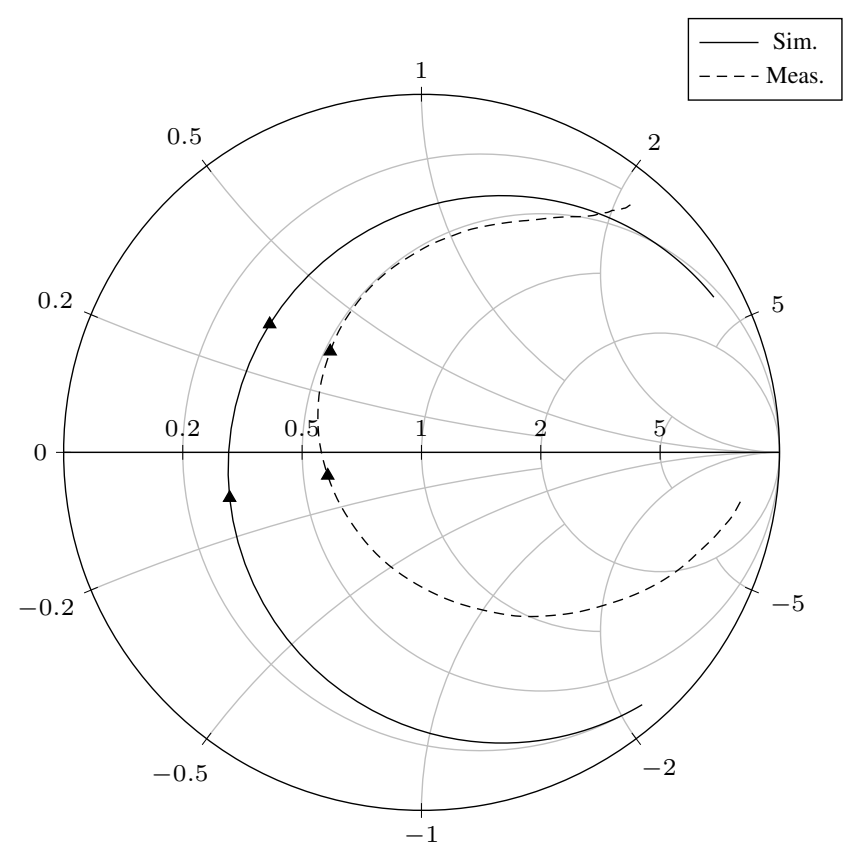

Fig. 5. Smith chart that shows the simulated (solid line) and measured (dashed line) reflection coefficient. The lower and upper frequency in the ISM band are marked by triangles.

measurements resulting in the higher real part of the input impedance which appears in Fig. 5. Furthermore, the effect of the cables can have had an impact. Especially outside the ISM band that the balun is designed for. The lower and more broadband reflection coefficient also account for the higher path gain in the measurements. Finally, it is noted that the head and ears used for the measurements is not the same as for the simulations.

The magnitude and phase of the simulated on-body gain calculated from Eq. 1 can be seen in Fig. 6 and Fig. 7, respectively. From Fig. 6 it is seen that the radiation pattern

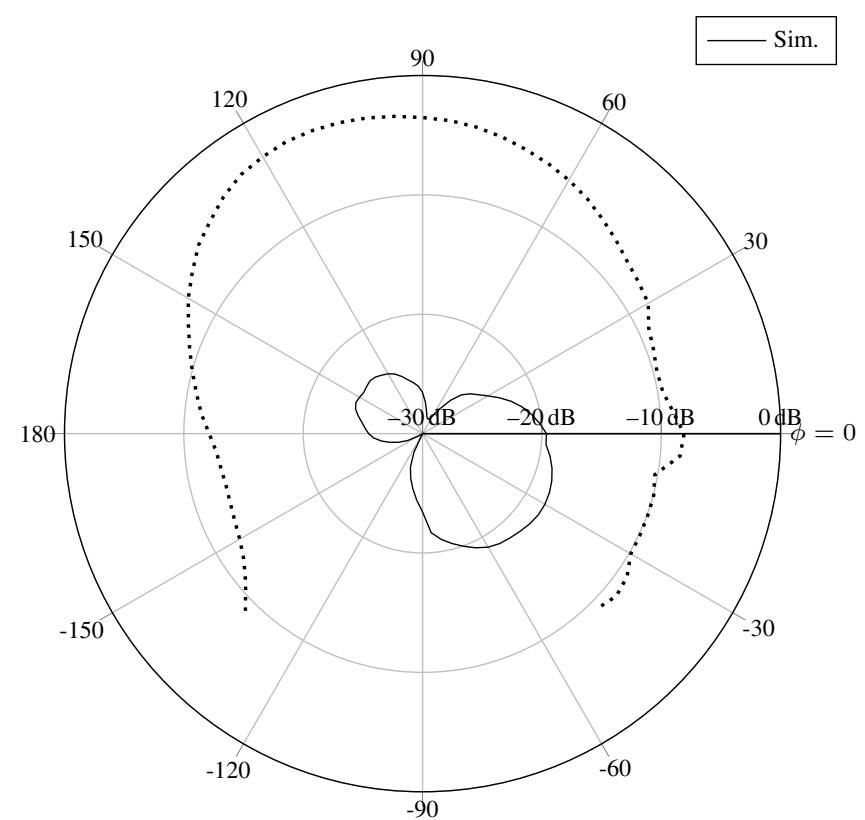

Fig. 6. Magnitude of the simulated on-body radiation pattern at $2.45 \mathrm{GHz}$ (solid line) on top of the head contour (dashed line).

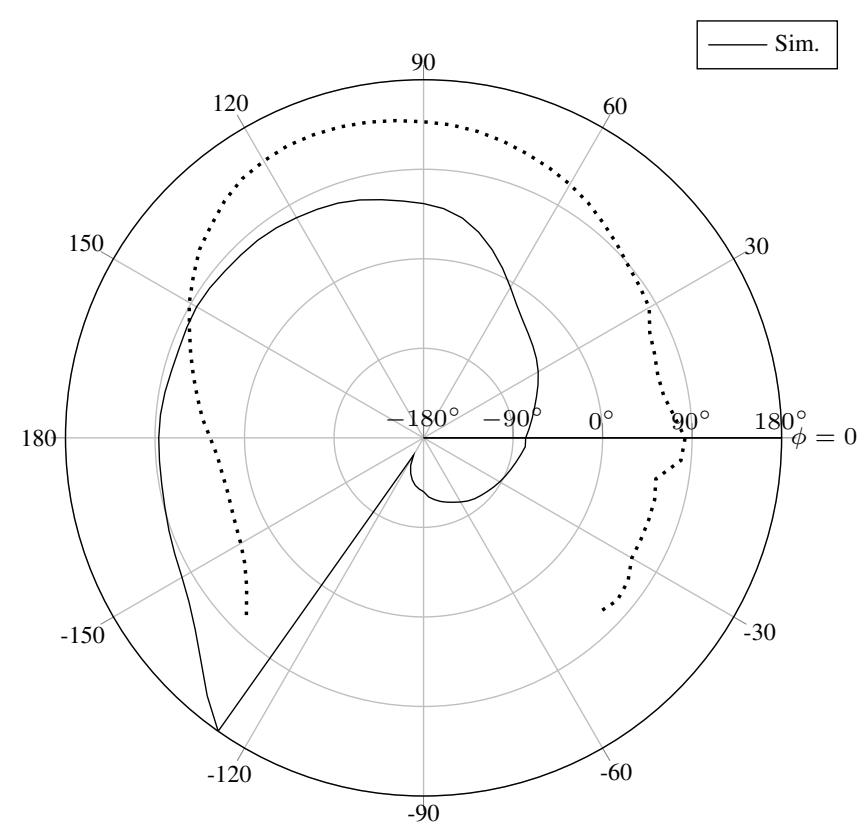

Fig. 7. Phase of the simulated on-body radiation pattern at $2.45 \mathrm{GHz}$ (solid line) on top of the head contour (dashed line).

has two lobes that are in opposite directions. The radiation patterns for other ITE antennas found in [7], [11] exhibit the same characteristic, which might indicate that this is a general trend for ITE antennas caused by the ear. Furthermore, it is seen that the lobe in the forward direction has the highest gain. The BTE antennas presented in the literature have had their main lobe in the backward direction, see for example [8]. Therefore, contrary to BTE antennas it is important to understand how the creeping wave propagates across the face. 
The previously mentioned E2E on-body path gain models [7], [8], which model the head with elliptic curves have been tested with antennas where the main path is behind the head. Since the face is not as well modeled with elliptic curves as the back of the head it is suggested that these models are tested with the main path around the front of the head. The phase of the on-body gain seen in Fig. 7 is seen to have a spiral characteristic corresponding to the shape of the antenna. This is different from the phase pattern in [11] which indicates that the phase is not only determined by the presence of the ear. Furthermore, it is noted that the two lobes are out-of-phase.

\section{CONCLUSion}

A novel ITE antenna has been designed, simulated, prototyped, and measured. It is the first ITE antenna, which is feasible to implement and yields a high enough path gain to be used with standard Bluetooth ICs. The measured and simulated E2E path gain at $2.45 \mathrm{GHz}$ was $-82.1 \mathrm{~dB}$ and $-85.9 \mathrm{~dB}$, respectively. The antenna was well matched in the entire ISM band. The on-body radiation pattern was presented and discussed. The radiation pattern showed two lobes. The main lobe was towards the front of the head opposite to what has been observed for BTE antennas. Therefore, it is suggested that it is investigated whether the existing models of the E2E path gain can be improved. Furthermore, it was found that it is possible to modify the phase of the on-body gain for ITE antennas through the antenna design.

\section{REFERENCES}

[1] S. H. Kvist, S. Özden, J. Thaysen, and K. B. Jakobsen, "Improvement of the ear-to-ear path gain at $2.45 \mathrm{GHz}$ using parasitic antenna element," in Proceedings of 6th European Conference on Antennas and Propagation, EuCAP 2012, Prague, Czech Republic, 2012, pp. 944 - 947.
[2] R. Chandra and A. J. Johansson, "Miniaturized antennas for link between binaural hearing aids," in 2010 Annual International Conference of the IEEE Engineering in Medicine and Biology Society, EMBC'10, Buenos Aires, Argentina, 2010, pp. 688-691.

[3] L. Huitema, S. Sufyar, C. Delaveaud, and R. D'Errico, "Miniature antenna effect on the ear-to-ear radio channel characteristics," in Proceedings of 6th European Conference on Antennas and Propagation, EuCAP 2012, Prague, Czech Republic, 2012, pp. 3402-3406.

[4] N. P. I. Kammersgaard, S. H. Kvist, J. Thaysen, and K. B. Jakobsen, "Inthe-ear spiral monopole antenna for hearing instruments," Electronics Letters, vol. 50, no. 21, pp. 1509-1511, 2014.

[5] S. Gabriel, R. W. Lau, and C. Gabriel, "The dielectric properties of biological tissues: III. Parametric models for the dielectric spectrum of tissues." Physics in medicine and biology, vol. 41, pp. 2271-2293, 1996.

[6] J. Ryckaert, P. De Doncker, R. Meys, A. de Le Hoye, and S. Donnay, "Channel model for wireless communication around human body," Electronics Letters, vol. 40, no. 9, pp. 543-544, 2004.

[7] R. Chandra and A. J. Johansson, "A link loss model for the on-body propagation channel for binaural hearing aids," IEEE Transactions on Antennas and Propagation, vol. 61, pp. 6180-6190, 2013.

[8] S. H. Kvist, J. Thaysen, and K. B. Jakobsen, "Ear-to-Ear On-Body Channel Model for Hearing Aid Applications," Accepted to IEEE Trans. Antennas Propagat., 2014.

[9] P. S. Hall, Y. Hao, Y. I. Nechayev, A. Alomalny, C. C. Constantinou, C. Parini, M. R. Kamarudin, T. Z. Salim, D. T. M. Hee, R. Dubrovka A. S. Owadally, W. Song, A. Serra, P. Nepa, M. Gallo, and M. Bozzetti, "Antennas and propagation for on-body communication systems," IEEE Antennas and Propagation Magazine, vol. 49, pp. 41-58, 2007.

[10] S. H. Kvist, J. Thaysen, and K. B. Jakobsen, "Polarization of unbalanced antennas for ear-to-ear on-body communications at $2.45 \mathrm{GHz}$," in LAPC 2011 - 2011 Loughborough Antennas and Propagation Conference, Loughborough, UK, 2011.

[11] N. P. I. Kammersgaard, S. H. Kvist, J. Thaysen, and K. B. Jakobsen, "Pinna Model for Hearing Instrument Applications," Accepted for 2014 Loughborough Antennas \& Propagation Conference, 2014. 